\title{
Gait-speed and oxygen flow during six-minute walk test predicts mortality in patients with advanced lung disease
}

\author{
Irina Timofte ${ }^{1}$, Adriano Tonelli ${ }^{2}$, Montserrat Diaz-Abad ${ }^{1}$, Avelino Verceles ${ }^{1}$, Nicholas Ladikos ${ }^{3}$, \\ Aldo Iacono ${ }^{4}$, Michael L. Terrin ${ }^{5}$, Marniker Wijesinha ${ }^{6}$, Olufemi Akindipe ${ }^{2}$, Maher Baz ${ }^{7}$
}

${ }^{1}$ Department of Medicine, Division of Pulmonary and Critical Care, University of Maryland School of Medicine, Baltimore, MD; ${ }^{2}$ Department of Pulmonary and Critical Care, Respiratory Institute, Cleveland Clinic, Cleveland, OH; ${ }^{3}$ Department of Pharmacy, Johns Hopkins Medicine/Suburban Hospital, Bethesda, MD; ${ }^{4}$ Department of Pulmonary and Critical Care, University of Maryland School of Medicine, Baltimore, MD; ${ }^{5}$ Department of Epidemiology and Public Health, University of Maryland School of Medicine, Baltimore, MD; ${ }^{6}$ Department of Epidemiology and Preventive Medicine, University of Maryland School of Medicine, Baltimore, MD; ${ }^{7}$ Department of Lung Transplantation, University of Kentucky, Lexington, KY, USA States

\begin{abstract}
The six-minute walk test (6MWT) is a useful tool to predict outcomes in patients with advanced lung diseases. Greater distance walked has been shown to have independent prognostic
\end{abstract}

Correspondence: Irina Timofte, Department of Medicine, Division of Pulmonary and Critical Care, University of Maryland School of Medicine, 110 South Paca Street, $2^{\text {nd }}$ Floor, Baltimore, MD 21201, USA. Tel. +1.410.328 2864 - Fax: +1.443.462 3045 .

E-mail: Irtimofte@SOM.umaryland.edu

Key words: Six-minute walk test, gait-speed, advanced lung disease, lung transplantation, survival.

Acknowledgements: We sincerely appreciate the outstanding job performed daily by the respiratory therapists at pulmonary function test laboratory of the University of Florida.

Contribution: IT, OA, MB, study design, data collection, manuscript drafting; AT, NL, study design, data analysis/statistics, manuscript drafting; MDA, study design, statistics, critical revision of the paper; $\mathrm{AV}$, data analysis/statistics, critical revision of the paper; AI, MLT, MW, data analysis/statistics, manuscript drafting. All authors have read and approved the manuscript.

Conflict of interest: All authors declare no conflict of interest.

Ethics approval: This retrospective study was approved by the University of Florida IRB. The study was performed at University of Florida, Gainesville, FL, United States.

Patient consent for publication: Not applicable.

Received for publication: 14 October 2019.

Accepted for publication: 21 January 2020.

${ }^{\circ}$ Copyright: the Author(s), 2020

Licensee PAGEPress, Italy

Monaldi Archives for Chest Disease 2020; 90:1186

doi: 10.4081/monaldi.2020.1186

This article is distributed under the terms of the Creative Commons Attribution Noncommercial License (by-nc 4.0) which permits any noncommercial use, distribution, and reproduction in any medium, provided the original author(s) and source are credited. value. We reviewed the medical records of 164 patients with advanced lung disease who underwent lung transplant evaluation. Results of the 6MWT (distance walked, oxygen required to maintain oxygen saturation $>90 \%$, and gait speed) were recorded and analyzed with respect to mortality. 6MWT mean oxygen $\left(\mathrm{O}_{2}\right)$ flow via nasal cannula was $3.5 \pm 3.7 \mathrm{l} / \mathrm{min}$. The distance walked in meters $(\mathrm{m})$ and percent predicted distance were inversely associated with mortality, hazard ratio (HR): 0.995 per meter (95\% CI 0.992-0.998) for walk distance in meters and 0.970 per $\%$ predicted distance $(95 \%$ CI $0.950-0.990)$. Patients who walked $<200$ meters [HR: 2.1 (95\% CI 1.1-4.0)] or $<45 \%$ of predicted, HR: 2.7 (95\% CI 1.2-5.7) had higher mortality. $\mathrm{O}_{2}$ flow during the test had a direct association with mortality (HR: 1.1 per $\mathrm{L} / \mathrm{min}$ (95\% CI 1.0-1.2). In multivariate analysis, $\mathrm{O}_{2}$ flow $>3.5 \mathrm{~L} / \mathrm{min}$ remained predictive of mortality, HR: $1.1 \mathrm{per} 1 / \mathrm{min}$ (95\% CI 1.0-1.2). Gait speed was higher in patients who survived through follow-up compared to patients who died (mean $0.83 \pm 0.35 \mathrm{~m} / \mathrm{s}$ vs $0.69 \pm 0.33 \mathrm{~m} / \mathrm{s}, \mathrm{p}=0.03)$. Gait speed $>0.8 \mathrm{~m} / \mathrm{s}$ was a predictor of survival, HR $3.4(1.1,10.6)$. In summary, distance walked and $\mathrm{O}_{2}$ flow during the 6MWT were predictors of mortality in patients with advanced lung disease. Patients who required more than $3.5 \mathrm{l} / \mathrm{m}$ of $\mathrm{O}_{2}$ to maintain oxygen saturation $>90 \%$ had a higher mortality. Faster gait speed during the $6 \mathrm{MWT}$ was also associated with better survival.

\section{Introduction}

The six-minute walk test (6MWT) is a simple functional test used in clinical practice and research for the assessment of exercise capacity in patients with moderate-to-severe cardiopulmonary disease. Since first being introduced by Butland in 1982 [1], this test has been particularly useful in assessing patients with chronic obstructive pulmonary disease (COPD) [2-4], pulmonary hypertension [5], interstitial lung disease [6], cystic fibrosis [7] and post-acute respiratory distress syndrome [8]. Lung transplantation is a therapeutic option for a broad spectrum of chronic, incapacitating pulmonary disease. The distance walked during the 6MWT is an important factor in guiding decisions about the time for lung transplant listing. More than three decades ago, Kadikar et al. showed that a 6MWT distance $<400$ meters was valuable in listing for lung transplantation [9]. Subsequently, the 
6MWT distance was incorporated in the calculation of the lung allocation score [10]. But, there are few disease-specific predictors to guide listing [11].

In patients with chronic lung diseases gait speeds reflect the overall level of impairment and offers an integrated index of physical activity. There are limited data regarding the importance of gait speed and oxygenation saturation during 6MWT in lung transplant evaluation.

We hypothesized that 6MWT walked distance, gait speed, and/or oxygen flow requirements are prognostic for patients with advanced lung disease evaluated for lung transplantation. The purpose of the study is to assess these in predicting mortality among advanced lung disease patients.

\section{Materials and Methods}

This study was a retrospective review of the records of 164 patients who underwent lung transplant evaluation at the University of Florida between March 2001 and November 2008. Lung transplant evaluation consisted of history, physical examination, laboratory testing, chest X-ray imaging, pulmonary function tests, 6MWT, electrocardiogram, right heart catheterization and interviews with social and psychology services. We searched the U.S. Social Security Death Index for vital status outcomes. This study was approved by the University of Florida IRB.

\section{Six-minute walk test}

We recorded the data from each subject first, 6MWT performed as part of the initial lung transplant evaluation according to the American Thoracic Society guidelines [12]. The tests were supervised by respiratory therapists with patients on the same supplemental oxygen as the patients were using at home unless the baseline pulse oximetry $\left(\mathrm{SpO}_{2}\right)$ measurement was $<90 \%$, for which oxygen flow was increased by $1 \mathrm{l} / \mathrm{min}$ every min until $\mathrm{SpO}_{2}$ $\geq 90 \%$ was achieved.

Patients were instructed to walk the corridor from one end to the other, as many laps as comfortable within the permitted time. Tests were stopped at six min or earlier for chest pain, intolerable dyspnea, gait instability, or other signs of severe distress [12]. In addition to the total distance walked, the oxygen flow required to keep a $\mathrm{SpO}_{2} \geq 90 \%$ was recorded. Before, during and immediately after the test, heart rate, blood pressure, $\mathrm{SpO}_{2}$ and Borg dyspnea scale were documented. Blood pressure was measured using an automated blood pressure monitor; heart rate was determined by a reliable waveform on pulse oximeter. The following formulas were used to predict walk distance for a calculation of percentage of predicted; for men, $6 \mathrm{MWD}=\left(7.57 \times\right.$ height $\left._{\mathrm{cm}}\right)-(5.02 \mathrm{x}$ age $)-(1.76$ $\mathrm{x}$ weight $\mathrm{kg})-309 \mathrm{~m}$; and for women, $6 \mathrm{MWD}=\left(2.11 \mathrm{x}\right.$ height $\left._{\mathrm{cm}}\right)-$ $\left(2.29 \mathrm{x}\right.$ weight $\left._{\mathrm{kg}}\right)-(5.78 \mathrm{x}$ age $)-667 \mathrm{~m}$ [9].

\section{Gait speed}

The gait speed data were obtained from the data measured during the 6MWT. Gait speed was calculated for each participant using total distance $(\mathrm{m})$ walked divided by total time walked in seconds.

\section{Outcome variables}

The outcome is mortality. Data regarding lung transplant listing, transplantation, and survival were obtained from a lung transplant database maintained by the institution and medical records. The U.S. Social Security Death Index [13] was queried when needed to confirm decease.

\section{Statistical analysis}

Continuous data are reported as mean \pm standard deviation (SD). Chi-square and Student's $t$-test were used to compare categorical and continuous variables, respectively. Survival from the date of 6MWT was analyzed, censored at the time of transplant and was analyzed according to the method of Kaplan-Meier. Survivors, awaiting lung transplantation, were censored at the end of the study $(03 / 13 / 2009)$. Univariate analysis was performed and multivariate analyses adjusted for age, gender and underlying disease (obstructive versus restrictive) were performed using Cox regression and expressed as hazard ratio (HR) with 95\% confidence interval (CI). 6MWT distances were assessed as discriminator values using receiver operating characteristic (ROC) curves, with mortality as the dependent variable. Similar ROC analyses were performed for gait speed and oxygen flow used during the 6MWT. Maximum followup time was 8 years. All $p$ values reported are two tailed. A p-value $\leq 0.05$ was considered significant. The analyses were performed using the statistical packages SPSS, version 17 (SPSS Inc., Chicago, IL, USA) and SAS Software, version 9.4

\section{Results}

\section{Patient's initial characteristics}

A total of 164 patients underwent lung transplant evaluation, age $51.8 \pm 0.9$ years and $58 \%$ women. Underlying diagnoses included COPD (33\%), idiopathic pulmonary fibrosis (22\%), cystic fibrosis $(11 \%)$, pulmonary fibrosis related to connective tissue disease (11\%), sarcoidosis (7\%), alpha-1 antitrypsin deficiency $(6 \%)$, pulmonary arterial hypertension (4\%), and others $(6 \%)$. Most patients had airflow obstruction (54\%) on spirometry. Right heart catheterization revealed mean pulmonary artery pressure 29.4 $\pm 19.7 \mathrm{~mm} \mathrm{Hg}$, cardiac output $4.97 \pm 1.3$ (1/min). Patient characteristics are presented in Table 1 .

\section{MWT results}

During the $6 \mathrm{MWT}$ a mean of $3.5 \pm 3.7 \mathrm{1} / \mathrm{min}$ of $\mathrm{O}_{2}$ flow was required by the cohort to complete the test. The average $6 \mathrm{MWD}$ was $261 \pm 123 \mathrm{~m}, 44 \pm 21 \%$ of predicted. Even with increasing $\mathrm{O}_{2}$ flow, mean $\mathrm{SpO}_{2}$ dropped $6.8 \pm 5.6 \%$ from the beginning to the end of evaluation and heart rate increased $21 \pm 13 \mathrm{bpm}$ during the test (Table 1).

\section{MWT parameters and survival}

Survival probability (transplantation censored) from the time of initial $6 \mathrm{MWT}$ was $89 \%$ and $59 \%$ at one and five years, respec- 
tively. The distance walked and percent of predicted distance were associated inversely with mortality - HR: 0.995 per meter $(95 \%$ CI $0.992-0.998$ ) for walk distance in meters and 0.970 per $\%$ predicted distance ( $5 \%$ CI $0.950-0.990)$. Mortality was increased for patients who walked $<200 \mathrm{~m}$ (HR: $2.1,95 \%$ CI: $1.1-4.0)$ or $<45 \%$ of predicted walk distance (HR: 2.7, 95\% CI: 1.2-5.7). The distance walked was analyzed by receiver operating characteristic (ROC) (Figure 1). The area under the curve was 0.7 (95\% CI 0.6$0.8, \mathrm{p}=0.001)$. The $\mathrm{O}_{2}$ flow $(1 / \mathrm{min})$ during the test had a direct association with mortality (HR: 1.1 for $\mathrm{O}_{2}$ flow per $1 / \mathrm{min}(95 \%$ CI 1.02-1.20)). The area under the curve (Figure 2) for the oxygen flow was 0.6 per $1 / \min (95 \%$ CI $0.99-1.19, \mathrm{p}=0.06)$. There was no association between the difference in heart rate or $\mathrm{SpO}_{2}$ before and at the end of exercise and mortality. In multivariate analysis only the $\mathrm{O}_{2}$ flow predicted mortality (HR: 1.1 for $\mathrm{O}_{2}$ flow per $1 / \mathrm{min}$; $95 \%$ CI: 1.01-1.2). Patients who required $>3.5 \mathrm{O}_{2} \mathrm{l} / \mathrm{min}$ had a higher one year and five-year mortality.

\section{Gait speed results}

Mean gait speed was $0.79 \mathrm{~m} / \mathrm{sec}$ (SD 0.34). Details regarding gait speed are presented in Table 2. The histogram comparing the distribution of gait speed in patients who survived with patients who did not survived is presented in Figure $3(\mathrm{p}=0.01)$. Survival was associated with faster gait speed (mean $0.8 \pm 0.35 \mathrm{~m} / \mathrm{s} v s$ $0.7 \pm 0.33 \mathrm{~m} / \mathrm{sec} ; \mathrm{p}=0.03)$. The area under the curve for

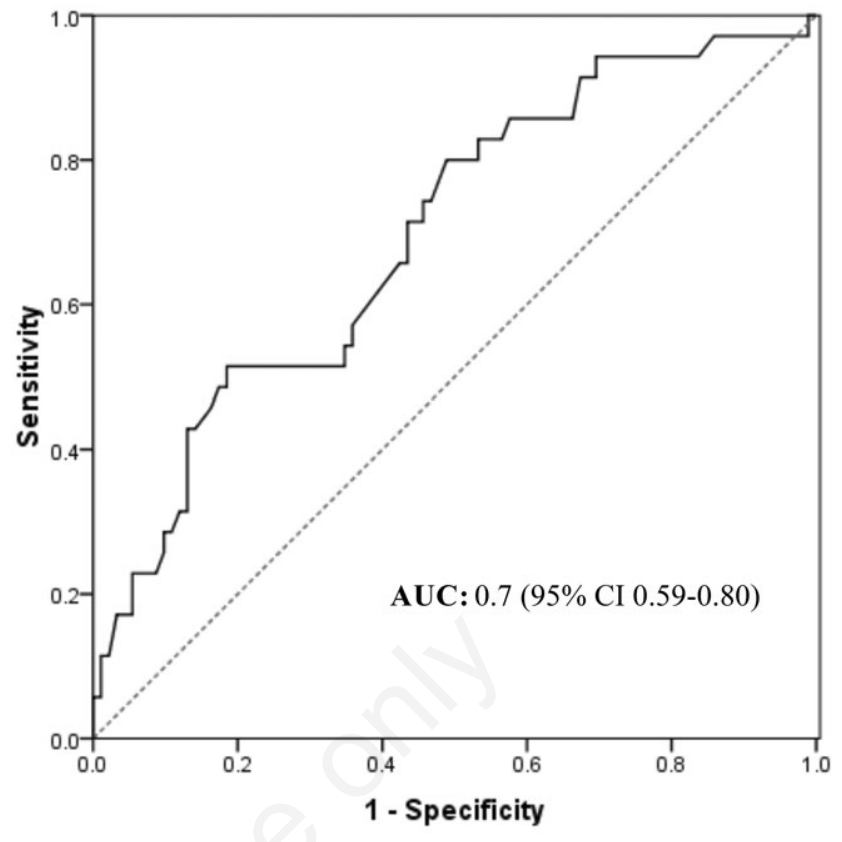

Figure 1. 6MWT distance Receiver operating characteristic (ROC) curve with mortality as outcome. AUC, area under the curve; $\mathbf{C I}$, confidence interval.

Table 1. Patient characteristics at baseline.

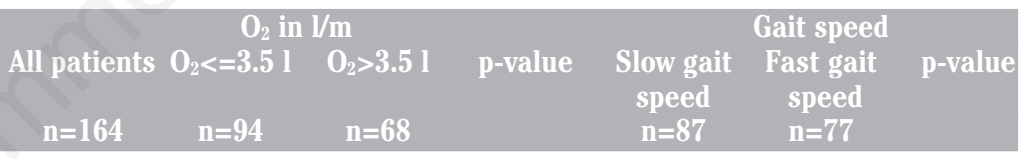

\begin{tabular}{|c|c|c|c|c|c|c|c|c|}
\hline \multicolumn{9}{|l|}{ Demographics } \\
\hline Age, years & Mean (SD) & $52(11.9)$ & $50(13)$ & $54(9)$ & 0.05 & $54(10.3)$ & $50(13.4)$ & 0.04 \\
\hline Gender & Female (\%) & $94(57 \%)$ & $50(53 \%)$ & $44(65 \%)$ & 0.14 & $50(57 \%)$ & $44(57 \%)$ & 0.96 \\
\hline \multicolumn{9}{|c|}{ Pulmonary function and six-minute walk test } \\
\hline Forced vital capacity percent of predicted & Mean (SD) & $46(14)$ & $46(13)$ & $46(15)$ & 0.92 & $47(14)$ & $46(13)$ & 0.69 \\
\hline Forced expiratory volume percent of predicted & Mean (SD) & $35(19)$ & $33(18)$ & $38(20)$ & 0.15 & $32(19)$ & $39(19)$ & 0.013 \\
\hline Total lung capacity & Mean (SD) & $90(43)$ & $97(44)$ & $81(37)$ & 0.02 & $100.2(44)$ & $78(38)$ & 0.014 \\
\hline Diffusion capacity for carbon monoxide & Mean (SD) & $32(19)$ & $34(20)$ & $29(14)$ & 0.1 & $27(15)$ & $39(20)$ & $<0.001$ \\
\hline 6-minute walk distance, meter & Mean (SD) & $263(123)$ & $283(132)$ & $231(102)$ & 0.005 & $181(74)$ & $356(100)$ & $<0.001$ \\
\hline $6 \mathrm{MWD}<200$ meter & $\mathrm{Nr}(\%)$ & $65(40 \%)$ & $34(36 \%)$ & $31(45 \%)$ & 0.22 & $57(66 \%)$ & $8(10 \%)$ & $<0.001$ \\
\hline Cardiac output, l/min & Mean (SD) & $4.9(1.3)$ & $5.0(1.2)$ & $4.9(1.4)$ & 0.41 & $4.8(1.1)$ & $5.1(1.4)$ & 0.17 \\
\hline Mean pulmonary Artery pressure mmhg & Mean (SD) & $20(1)$ & $27(8)$ & $32(12)$ & 0.02 & $30(10)$ & $28(9.5)$ & 0.14 \\
\hline Ejection fraction & Mean (SD) & $57(8.5)$ & $58(6.8)$ & $57(10.3)$ & 0.34 & $57(8.7)$ & $58(8.2)$ & 0.8 \\
\hline \multicolumn{9}{|l|}{ Transplant characteristics } \\
\hline Underlying disease (obstructive $v s$ restrictive) & Obstructive (\%) & $88(53 \%)$ & $57(60 \%)$ & $31(45 \%)$ & 0.27 & $55(63 \%)$ & $34(38 \%)$ & 0.014 \\
\hline Patient underwent transplant & Transplanted (\%) & $48(29 \%)$ & $31(\% 33)$ & $17(25 \%)$ & 0.27 & $22(25 \%)$ & $27(35 \%)$ & 0.17 \\
\hline Patient died before transplant & Died $(\%)$ & $31(19 \%)$ & $15(16 \%)$ & $16(24 \%)$ & 0.22 & $22(25 \%)$ & $9(12 \%)$ & 0.026 \\
\hline \multicolumn{9}{|l|}{ Type of lung transplant } \\
\hline & Single (\%) & $23(14 \%)$ & $18(58 \%)$ & $5(29 \%)$ & 0.06 & $8(36 \%)$ & $15(64 \%)$ & 0.11 \\
\hline & Double (\%) & $25(15 \%)$ & $13(42 \%)$ & $12(70 \%)$ & & $14(63 \%)$ & $11(41 \%)$ & \\
\hline
\end{tabular}


dichotomized gait speed receiver operating characteristics (Figure 4) was 0.65 (95\% CI 0.052-0.68, $\mathrm{p}=0.01)$.

\section{Patient's outcomes}

Twenty-nine (29) \% of patients underwent lung transplantation of which 23 (14\%) underwent single and 25 (15\%) underwent double lung transplantation; $19 \%$ of patients died before lung transplantation.

The Kaplan-Meier plot displaying the survival censoring transplant for the full cohort is shown in Figure 5. The estimated survival at 5 years was $56 \%$ for the overall cohort. A Kaplan-Meier plot comparing the survival censoring transplant between the patients with fast gait speed $(>0.8 \mathrm{~m} / \mathrm{min})$ and slow gait speed ( $\leq$ $0.8 \mathrm{~m} / \mathrm{min}$ ) is shown in Figure 6, at 5 years $65 \%$ in the fast gait speed and $49 \%$ in the slow gait speed group.

\section{Discussion}

In the present study of patients with heterogeneous advanced lung diseases evaluated for lung transplantation, we found that the amount of oxygen required to maintain $\mathrm{SpO}_{2} \geq 90 \%$, distance walked during 6MWT, and gait speed were associated with mortality. A distance of $<200 \mathrm{~m}$ predicted increased mortality. In multivariate analysis baseline $\mathrm{O}_{2}$ flow $(>3.5 \mathrm{~L} / \mathrm{min})$ to maintain $\mathrm{O}_{2}$ saturation $>90 \%$ was an independent predictor of mortality.

Since the first successful human lung transplant in 1983, there have been increasing numbers of lung transplants performed every year. However, the list of potential candidates for lung transplantation exceeds the number of donors. Also, there is a critical balance between transplanting patients too early or too late. In an effort to direct lung transplantation to more urgently ill patients, the lung allocation score (LAS) system was implemented in 2005 and dramatically altered the way in which donor lungs were allocated in the United States. There has been a decrease in mortality on the wait list since $2005[11,14,15]$.

Previous studies showed that 6MWD is an independent predictor of all-cause as well as pulmonary-related mortality. COPD patients who walked $<300 \mathrm{~m}$ had a significantly greater mortality rate [16]. In patients with idiopathic pulmonary arterial hypertension (IPAH), 6MWD $<300 \mathrm{~m}$ was associated with increased mortality [17]. In patients with idiopathic pulmonary fibrosis, 6MWD $<200 \mathrm{~m}$ was associated with mortality [18], results similar to our study. Castleberry et al. reported the association between the 6MWD and survival after lung transplantation [19]. In his study, 6MWD is significantly associated with post-transplant survival,

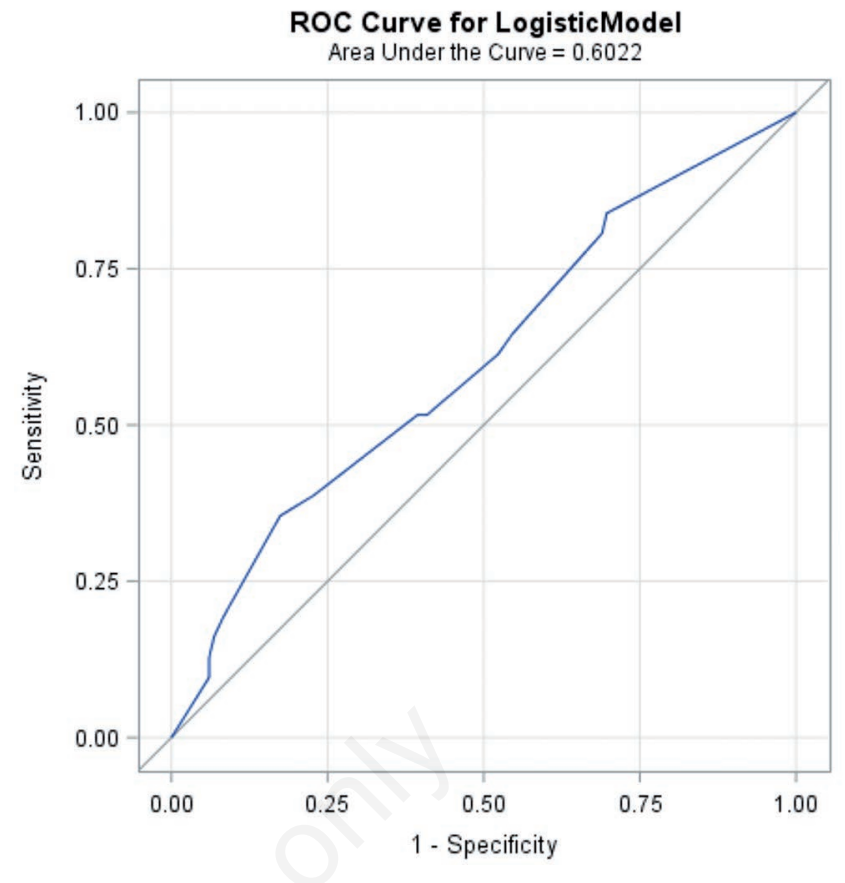

Figure 2. Receiver operating characteristic (ROC) curve for oxygen flow with mortality as outcome.

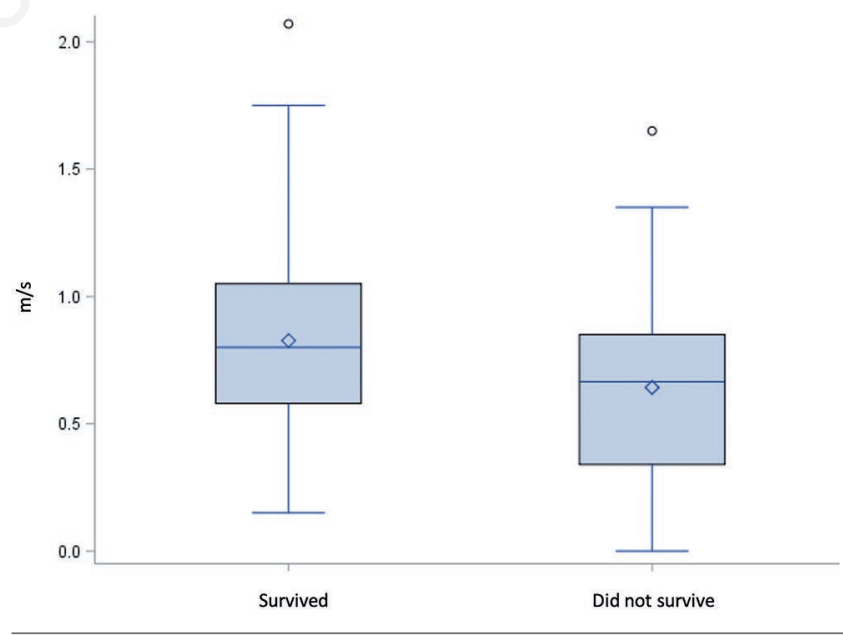

Figure 3. Box and whisker plot comparing the distribution of gait speeds in patients who survived with patients who did not survive.

Table 2. Gait speed characteristics.

\begin{tabular}{|c|c|c|c|c|}
\hline & & $\begin{array}{l}\text { All patients } \\
n=164\end{array}$ & $\begin{array}{c}\text { Slow gait speed } \\
n=87\end{array}$ & $\begin{array}{l}\text { Fast gait speed } \\
\qquad=77\end{array}$ \\
\hline Gait speed & Mean (SD) & $0.79(0.34)$ & $0.54(0.17)$ & $1.08(0.22)$ \\
\hline \multicolumn{5}{|l|}{ Outcomes } \\
\hline Patient underwent transplant & Transplanted (\%) & $48(29 \%)$ & $22(25 \%)$ & $27(35 \%)$ \\
\hline Patient died before transplant & Died (\%) & $31(19 \%)$ & $22(25 \%)$ & $9(12 \%)$ \\
\hline
\end{tabular}


and increasing 6MWD was associated with significantly lower overall hazard of death.

In the present study we also have shown that the maximum $\mathrm{O}_{2}$ flow used during the 6MWT had a significant association with

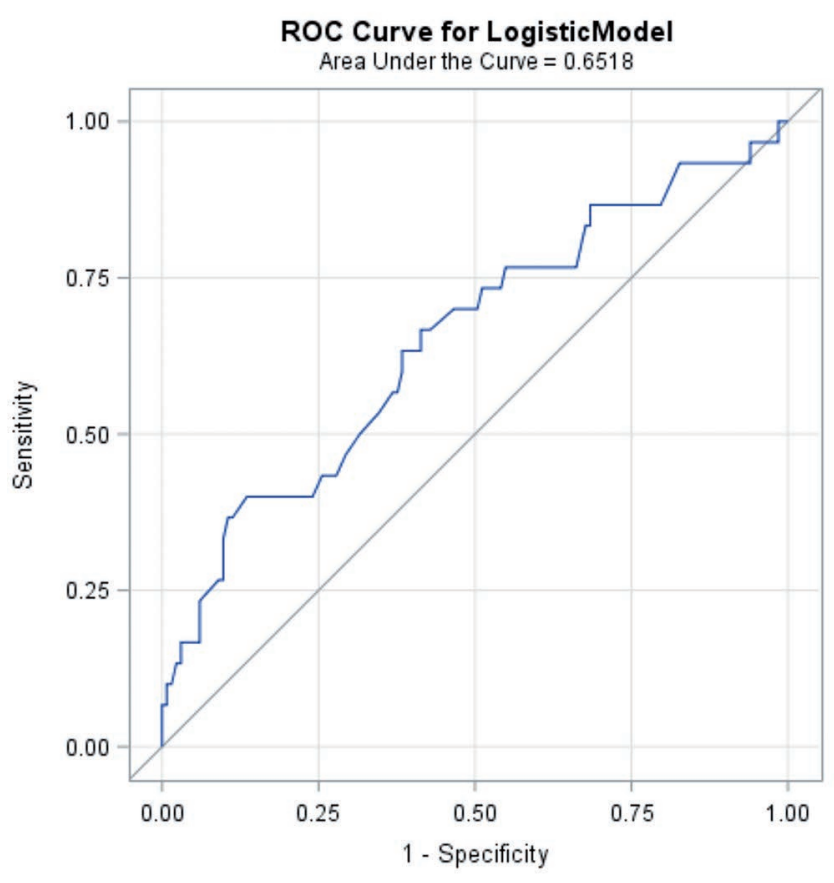

Figure 4. Receiver operating characteristic (ROC) curve for gait speed $>0.8 \mathrm{~m} / \mathrm{s}$ with mortality as outcome. mortality. Patients who required $>3.5 \mathrm{O}_{2} \mathrm{l} / \mathrm{min}$ to maintain $\mathrm{O}_{2}$ saturation $>90 \%$, had reduced 1-year and the 5-year survival. Although mortality is related to use of oxygen therapy in patients with COPD [4], for patients with sarcoidosis awaiting lung transplantation [20] or patients with idiopathic pulmonary fibrosis complicated by pulmonary arterial hypertension [21], no specific cut off for $\mathrm{O}_{2}$ flow is documented in the literature. The prognostic value of $\mathrm{O}_{2}$ flow during $6 \mathrm{MWT}$ to maintain $\mathrm{O}_{2}$ saturation $>90 \%$ is a new predictor of mortality in patients with advanced lung disease undergoing lung transplant evaluation.

A recent article demonstrated that gait speed is independently associated with 6MWD in patients with severe chronic lung disease [22]. For COPD patients, gait speed had a strong correlation with pulmonary function, functional capacity, and health-related quality of life [23-25]. Though gait speed has been shown to predict survival in older adults [26], the association between gait speed and survival in patients with severe lung disease evaluated for lung transplantation has not been thoroughly evaluated. Our study demonstrates that gait speed predicts mortality in patients with advanced lung disease.

We are interested in gait speed because it is a simple method for patient testing, largely independent of time and setting. Our study shows that faster gait speed is associated with better survival and could substitute for the 6MWT.

The study has limitations associated with the retrospective nature of our database. Data regarding dyspnea and muscle fatigue at the end of the test are not included in our database; therefore, those outcomes were not analyzed. Although a previous study showed that decreases in $\mathrm{SpO}_{2}$ during exercise has prognostic value [18], our design did not allow us to demonstrate an association between the change in $\mathrm{SpO}_{2}$ before and at the end of exercise and mortality. A relatively small sample size in a single center cohort limits our generalizability.

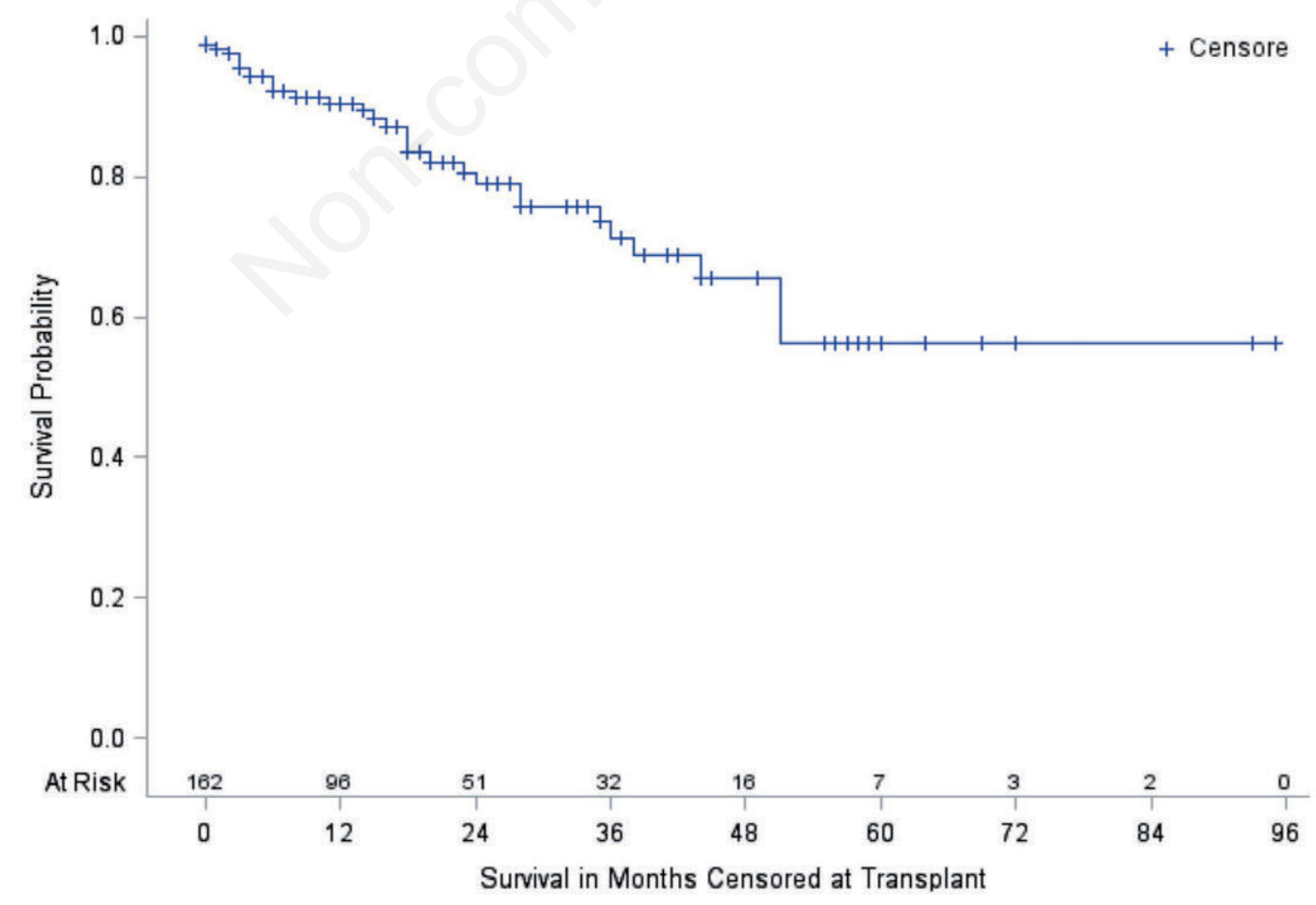

Figure 5. Survival for cohort censored at transplant. 


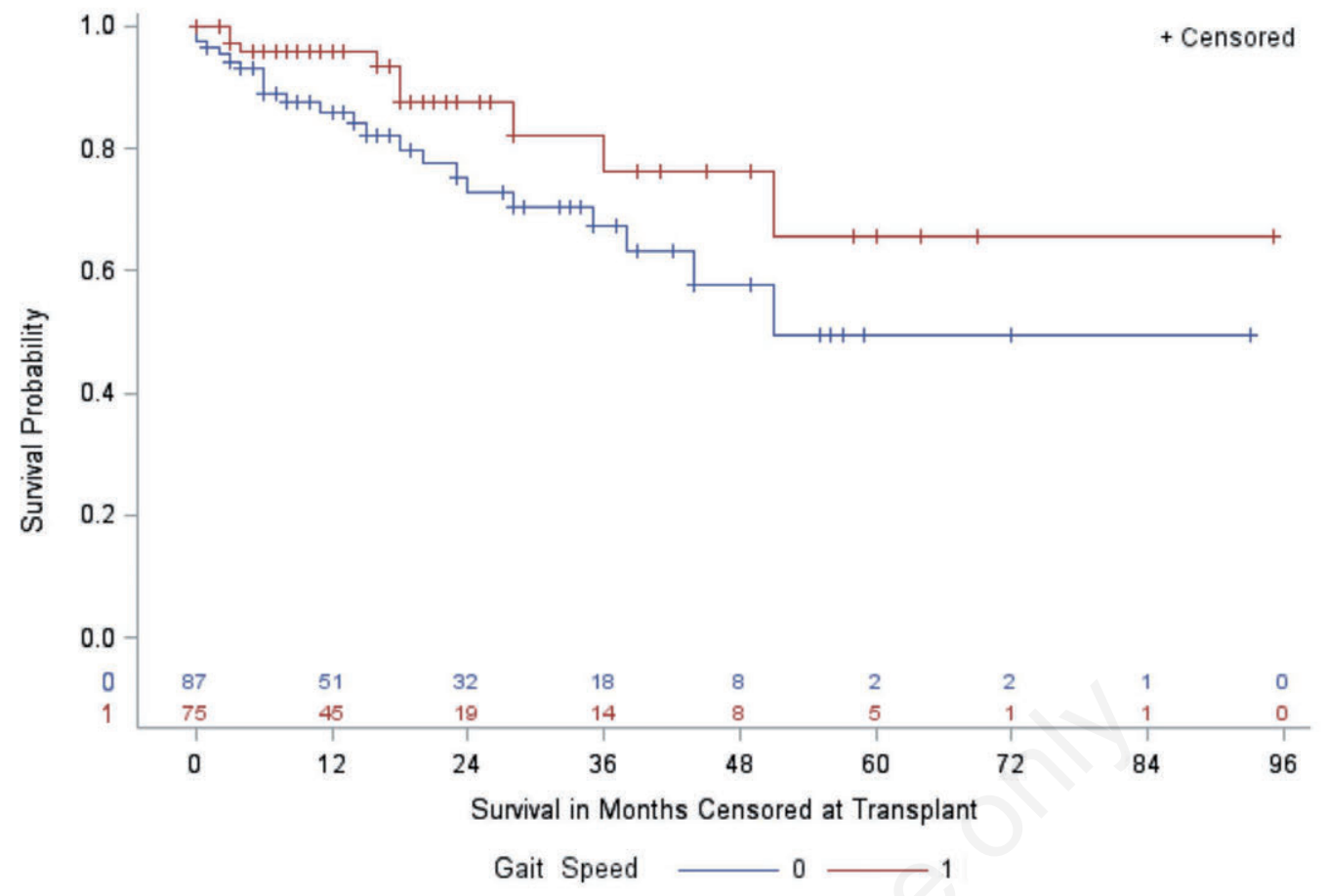

Figure 6. Transplant-free survival comparing patients with fast gate speed $(>0.8 \mathrm{~m} / \mathrm{min})$ and slow gait $s p e e d(\leq 0.8 \mathrm{~m} / \mathrm{min})$.

\section{Conclusions}

Our study showed that oxygen flow to maintain $\mathrm{O}_{2}$ saturation $>90 \%$ during a $6 \mathrm{MWT}$ predicted mortality in a cohort of advanced lung disease patients evaluated for lung transplantation and may be valuable for predicting wait list mortality. Faster gait speed is associated with better survival.

\section{References}

1. Butland RJ, Pang J, Gross ER, et al. Two-, six-, and 12-minute walking tests in respiratory disease. Br Med J (Clin Res Ed) 1982 29;284:1607-8.

2. Dajczman E, Wardini R, Kasymjanova G, et al. Six-minute walk distance is a predictor of survival in patients with chronic obstructive pulmonary disease undergoing pulmonary rehabilitation. Can Respir J 2015;22:225-9.

3. Enfield K, Gammon S, Floyd J, et al. Six-minute walk distance in patients with severe end-stage COPD: association with survival after inpatient pulmonary rehabilitation. J Cardiopulm Rehabil Prev 2010;30:195-202.

4. Martinez FJ, Foster G, Curtis JL, et al. Predictors of mortality in patients with emphysema and severe airflow obstruction. Am J Respir Crit Care Med 2006;173:1326-34.

5. Demir R, Küçükoğlu MS. Six-minute walk test in pulmonary arterial hypertension. Anatol J Cardiol 2015;15:249-54.

6. Brown AW, Nathan SD. The value and application of the 6minute-walk test in idiopathic pulmonary fibrosis. Ann Am Thorac Soc 2018;15:3-10.
7. Martin C, Chapron J, Hubert D, et al. Prognostic value of six minute walk test in cystic fibrosis adults. Respir Med 2013;107:1881-7.

8. Herridge MS, Cheung AM, Tansey CM, et al. One-year outcomes in survivors of the acute respiratory distress syndrome. N Engl J Med 2003;348:683-93.

9. Kadikar A, Maurer J, Kesten S. The six-minute walk test: a guide to assessment for lung transplantation. J Heart Lung Transplant 1997;16:313-9.

10. Gottlieb J. Lung allocation. J Thorac Dis 2017;9:2670.

11. Valapour M, Skeans MA, Smith JM, et al. OPTN/SRTR 2015 Annual Data Report: Lung. Am J Transplant 2017;17 (s1):357.

12. ATS Committee on Proficiency Standards for Clinical Pulmonary Function Laboratories. ATS statement: guidelines for the six-minute walk test. Am J Respir Crit Care Med 2002;166:111-7.

13. Rootsweb, Social Security Death Index. Accessed on: December 2008. Available from: http://ssdi.rootsweb.ancestry.com/

14. Egan TM, Edwards LB. Effect of the lung allocation score on lung transplantation in the United States. J Heart Lung Transplant 2016;35:433-9.

15. Egan TM, Murray S, Bustami RT, et al. Development of the new lung allocation system in the United States. Am J Transplant 2006 6:1212-27.

16. Pinto-Plata V, Cote C, Cabral H, et al. The 6-min walk distance: change over time and value as a predictor of survival in severe COPD. Eur Respir J 2004;23:28-33.

17. Paciocco G, Martinez FJ, Bossone E, et al. Oxygen desaturation on the six-minute walk test and mortality in untreated primary pulmonary hypertension. Eur Respir J 2001;17:647-52. 
18. Lederer DJ, Arcasoy SM, Wilt JS, et al. Six-minute walk distance predicts waiting list survival in idiopathic pulmonary fibrosis. Am J Respir Crit Care Med 2006;174:659-64.

19. Castleberry AW, Englum BR, Snyder LD, et al. The utility of preoperative six-minute-walk distance in lung transplantation. Am J Respir Crit Care Med 2015;192:843-52.

20. Shorr AF, Davies DB, Nathan SD. Predicting mortality in patients with sarcoidosis awaiting lung transplantation. Chest 2003;124:922-8.

21. Lettieri CJ, Nathan SD, Barnett SD, et al. Prevalence and outcomes of pulmonary arterial hypertension in advanced idiopathic pulmonary fibrosis. Chest 2006;129:746-52.

22. DePew ZS, Karpman C, Novotny PJ, Benzo RP. Correlations between gait speed, 6-minute walk distance, physical activity, and self-efficacy in patients with severe chronic lung disease. Respir Care 2013;58:2113-9.

23. Butcher SJ, Meshke JM, Sheppard MS. Reductions in functional balance, coordination, and mobility measures among patients with stable chronic obstructive pulmonary disease. J Cardiopulm Rehabil 2004;24:274-80.

24. Ilgin D, Ozalevli S, Kilinc O, et al. Gait speed as a functional capacity indicator in patients with chronic obstructive pulmonary disease. Ann Thoracic Med 2011;6:141-6.

25. Kon SS, Patel MS, Canavan JL, et al. Reliability and validity of the four metre gait speed in COPD. Eur Respir J 2013;42:333-40.

26. Studenski S, Perera S, Patel K, et al. Gait speed and survival in older adults. JAMA 2011;305:50-8. 